\title{
UM CIRCUNVOLVER DA NOÇÃO DE NADA
}

Gabriel Salvi Philipson* gsphilipson@gmail.com

RESUMO Este artigo circunscreve a noção de nada absoluto cunhada pela Escola de Kyoto, na intenção de analisar tanto a possibilidade de que exista uma relação intrínseca entre a experiência da linguagem japonesa e essa tentativa contemporânea e historicamente única de realizar um pensamento que conjunte as tradições ocidentais e orientais da filosofia, quanto as diferenças de abordagens filosóficas internas à própria Escola.

Palavras-chave Nada absoluto, Escola de Kyoto, linguagem.

ABSTRACT The purpose of this article is to circumscribe the notion of absolute nothingness created by Kyoto School. The intention is to analyze not only if there is an intrinsic relation between the experience of the Japanese language and the contemporary and historically unique attempt of performing a thought that links the philosophical tradition of both West and East, but also if there are different philosophical approaches in the inner of the Kyoto School itself.

Keywords Absolute nothingness, Kyoto School, language.

* Mestrando junto ao Prof. Marcus Vinicius Mazzari no Departamento de Teoria Literária e Literatura Comparada da USP. Agradeço à FAPESP pelo financiamento de minha pesquisa de Iniciação Científica, sem o qual a escrita deste artigo não seria possível. Também agradeço à orientação e aos pertinentes comentários do Prof. Dr. Marcus Sacrini Ayrez Ferraz quando da escrita desse texto. Artigo recebido em 13/09/2014 e aprovado em 14/02/2015. 


\section{A aparição do vazio: o nada absoluto surge da descontinuidade}

The fabric of history is rent asunder, and the 'world' in which we live reveals itself as an abyss. From the bottom of the self the world and the self together become a question - at the same time a historical and a metaphysical question. (Nishitani, 1990, p. 4)

Nosso interesse neste texto reside em circunvolver de modo rigoroso alguns aspectos da tentativa de determinados autores japoneses de formar na época contemporânea um pensamento autêntico. Esta tentativa, no entanto, não reside exatamente em uma busca por encontrar um lugar para a filosofia oriental por meio do conceito de nada, um dos mais bem desenvolvidos e aprofundados no percurso histórico desta tradição. Seria mais adequado percebê-la, na verdade, como uma busca por realizar algo ainda mais ousado, a saber, produzir um pensamento filosófico que fosse capaz de ter em conta e de colocar em diálogo ambas as tradições culturais de maior alcance da humanidade.

Ocorre, no entanto, que esse empreendimento grandioso de realizar um pensamento global constituiu-se contraditoriamente ao mesmo tempo como uma salvaguarda de uma enorme tradição cultural e filosófica que sofria com a possibilidade de ser extinta, ao entrar em contato com a cultura vencedora, estandarte, que diminuiu e vem diminuindo virtualmente por meio da técnica as distâncias espaciais. É nesse ambiente contraditório, em que um esforço contemporâneo do pensamento de se universalizar e globalizar tem que recuperar e transformar uma cultura tradicional - muito por conta dos preconceitos aos quais a filosofia oriental esteve submetida ao longo de sua breve relação com a tradição ocidental durante toda modernidade -, que podemos ver reflorescer a noção de nada com uma força peculiar. Esta funcionaria paradoxalmente ao mesmo tempo como uma espécie de barreira que garantiria a permanência e a revitalização de uma série de embates filosóficos históricos da tradição oriental, como também um horizonte para o qual essa nova cultura globalizada em formação estaria direcionada.

Nos três textos que iremos circunvolver, buscando analisar alguns momentos dessa tentativa em três autores e momentos históricos distintos, veremos que tal empreendimento do pensamento sempre tem como base uma leitura histórico-filosófica e rigorosa de autores ocidentais tais como Hegel, Nietzsche e Heidegger. Paralelamente a esse procedimento interpretativo comum a tais autores, encontra-se também uma busca por igualar e contraditoriamente adequar, confrontar, sintetizar, resguardar e suplantar uma certa visão de mundo oriental, assim como os esquemas conceituais que a 
formam. E aquilo que se mantém como um fundo nessa relação, que se mostra como uma noção profícua para o aprofundamento dessa tensão é a noção de nada, a qual tem como procedência de modo mais característico a tradição de pensamento budista, mas que historicamente se desenvolve em meio às mais diversas correntes de pensamento no Oriente, e apenas a partir desse processo conflituoso pode ser compreendida.

Temos em vista neste artigo de algum modo inverter a visão do panorama aqui esboçado. Pretende-se isso ao se partir da perspectiva, até onde seja possível, do leitor ingênuo que pela primeira vez se debruça sobre o tema e busca se orientar no interior dos textos dos diversos autores ali presentes. Com isso, estaremos em alguma medida realizando o caminho inverso do dos autores analisados, ao darmos ênfase à observação desse conceito que se mantém, se perpetua e, a despeito de sua história anterior, se desenvolve ao se sujeitar a tal faustoso empreendimento do pensamento, durante alguns dos diversos momentos desse tortuoso percurso.

Propomo-nos analisar como esse conceito se desdobra em três textos presentes em uma das obras atuais que mais tem servido para divulgar a Escola de Kyoto, a saber, o livro editado por Ohashi em 1990 e reeditado em 2011 intitulado simplesmente Die Philosophie der Kyôto-Schule (A filosofia da Escola de Kyoto).

Assim, observaremos como, a partir da organização histórica segundo a qual este livro está disposto, o primeiro confronto ao qual o nada é submetido é contra o (e ao mesmo tempo junto ao) hegelianismo e o (neo)kantismo do fin-de-siécle. Em Autoidentidade e continuidade do mundo (1934), Nishida parece pensar que um desenvolvimento mais aprofundado da noção de nada poderia e deveria ter modificado a própria noção de sujeito e de dialética em Hegel. Isso significa dizer no limite que tanto o ponto de partida de Hegel quanto sua lógica já apresentariam de antemão problemas filosóficos, o que abriria espaço para se pensar uma nova filosofia calcada, justamente, no nada absoluto.

Tendo mínima e suficientemente analisado isso, nosso percurso circunvolvente nos levará ao texto de Ueda já conhecido do leitor brasileiro graças à boa tradução de Florentino Neto, O nada absoluto no zen em Eckhart e em Nietzsche (1990). A partir desse momento teremos em vista, além do mais, uma comparação interna à própria Escola de Kyoto. Neste texto, estamos interessados em perceber o desenvolvimento da noção de nada quando confrontada com momentos especiais da filosofia ocidental: por um lado, o desenvolvimento em Eckhart daquilo que Ueda chama de teologia negativa e que pode para alguns desembocar em alguma espécie de misticismo (e que por 
isso foi muitas vezes deixado em segundo plano na história da filosofia). Nesse pensamento estaria, na tradição ocidental, a mais aprofundada e coerente noção de nada. Por outro lado, Ueda confronta tal noção com o pensamento do maior crítico ocidental da filosofia ocidental, Nietzsche, o qual, em certa medida, realiza tal crítica muito em função de um desenvolvimento da desconstrução da filosofia da identidade e da substancialidade, abrindo caminho para que seja pensada a noção de nada com a qual nos ocupamos. Interessa-nos observar que em ambos os autores, a despeito de sua radicalidade e maior proximidade com certas noções caras à tradição filosófica oriental, Ueda verá uma certa incapacidade de dar um passo que para ele é o passo fundamental, e que se constitui talvez naquilo que determina a visão de mundo budista. Assim como a especificação e detalhamento desse passo serão discutidos no decorrer do texto, não deixaremos de fazer também algumas considerações que achamos necessárias sobre essa interpretação uediana.

Por fim, o texto de Tsujimura - $A$ verdade do ser e o nada absoluto, que é a conclusão de uma obra maior, o A questão do ser e o nada absoluto (1971) desenvolve a noção de nada absoluto em comparação com o empreendimento também grandioso de Heidegger de desconstrução da tradição metafísica ocidental. Será neste momento que o leitor ingênuo se deparará com uma certa contradição entre as noções de nada no interior mesmo da Escola de Kyoto, as quais em certa medida significam um desenvolvimento, em direções distintas, do próprio projeto nishidiano, o que lhe dará o que pensar: será ela fruto da subjetividade desse leitor, consequência das tenções da filosofia contemporânea com a qual a noção de nada se submeteu, ou ainda alguma outra coisa?

1.1 Autoidentidade e continuidade: dialética hegeliana, antidialética e experiência pura

Nele, trata-se de investigar, por um lado, aquilo que faz de uma coisa ser uma coisa, na medida em que unifica o tudo que é - ou seja, a autoidentidade - e, por outro, aquilo que permite de certa forma que o plural torne-se um, i.e. que permite que entre unidades haja uma relação a tal ponto que se tornam uma outra unidade - ou seja, a continuidade. Esse problema já coloca de partida uma recusa pela simplificação 'um ou pluralidade'. Ao contrário de simplificar, já indica que se perceba um um plural e uma pluralidade única. Isso significa que, e se a própria pergunta coloca seu terreno de jogo e indica um caminho, aqui se abre desde o início uma possibilidade de multivocidade de conceitos. 
O que eu chamo de autoidentidade não significa apenas que uma coisa seja uma coisa, mas que algo se unifique, na medida em que se diferencia sem se diferenciar, assim como na medida em que seja plural sendo um. Também aquilo que eu chamo de 'continuidade' significa aquilo que algo unifica na medida em que é plural sendo um. O mero um não pode ser chamado de continuidade, e do mesmo modo o mero plural não pode ser assim chamado. (Nishida, 2011, p. 56, minha tradução)

Aqui, vale a pena indicar duas pressuposições às quais Nishida faz referências indiretas.

1. A primeira é que este texto se movimenta sobretudo em proximidade com Hegel, isto é, seu âmbito é o da dialética, em que termos opostos se identificam e sua contradição produz um terceiro termo que contém os dois primeiros e que é o primeiro. Mesmo que se movimente nesse terreno, Nishida propõe uma leitura crítica e mais radical desse esquema, pois, embora admire em Hegel que a identidade de algo sempre se dá a partir de seu oposto, Hegel não foi capaz, para ele, de ir além da posição de uma dialética subjetiva, vide Nishida (2011, p. 62): ${ }^{1}$ para a dissolução dessa lógica subjetivista, que Nishida vê como algo particular da filosofia ocidental ${ }^{2}$ e de seu consequente niilismo, a noção de nada absoluto é fundamental.

Seu embasamento teórico ocorre a partir da noção de experiência pura oriunda de sua influência de William James:

2. Em Sobre o bem: uma filosofia da experiência pura (1924), seu primeiro livro, interessa a Nishida (2001) principalmente argumentar em vista a propor uma experiência pura que seja anterior à divisão sujeito-objeto. É que "originalmente existe para a experiência nem um dentro nem um fora. O que a faz pura é a sua unidade, não seu modo" (Nishida, 2001, p. 34). Ele oferece dois exemplos dessa experiência pura unitária: a consciência do recém-nascido, que é uma "unidade confusa e indeterminada, em que até mesmo claro e escuro não estão separados" (Nishida, 2001, p. 33) e aquilo que acontece com a percepção de um momento. Para ele, mesmo se aceitarmos que com um olhar conseguimos perceber o todo de uma coisa, ocorre que, se observarmos bem, Nishida afirma, a atenção mesma varia paralelamente à

1 Trataremos disso adiante, na sessão 2.2.1.

2 Sobre a crítica de Nishida à filosofia ocidental de seu tempo, ver: Jacinto Zavala, 'Heidegger na filosofia nishidiana'. In: Florentino Neto (org.) e Giacoia Jr. (org.) (2012). Nesse artigo, Zavala realiza uma vasta e instigante pesquisa nas cartas de Nishida a fim de mostrar os vários momentos da sua recepção do neokantismo, da fenomenologia de Husserl e dos textos de Heidegger dos anos 30 (i.e. do considerado 'primeiro' Heidegger). Grosso modo, a crítica de Nishida a todos esses autores e correntes está de acordo com as consequências do percurso de reflexão deste texto. É que há em todos eles algum tipo de subjetivação, intelectualismo: eles não conseguem, de um modo ou de outro, sair do sujeito, o que os leva a não compreenderem o presente como temporalidade primeva, e não conseguirem abordar a noção de nada de modo adequado. Isso não se aplica, no entanto, ao que me parece, à noção de nada no chamado 'segundo' Heidegger, mas este estudo não é um local apropriado para se aprofundar nessa relação. A indicação dessa questão, no entanto, ajuda-nos a instaurar o horizonte de valor de nossa pesquisa. 
movimentação dos olhos até que o todo esteja apreendido (vide Nishida, 2001, p. 34). Além disso, essa experiência pura não é cega em sentido kantiano de uma intuição sem categorias, conquanto o todo da nossa experiência, incluindo tanto a percepção sensorial quanto a intuição intelectual. Em outras palavras, a experiência pura contém todo o tipo de experiência, assim como a luz branca contém implicitamente todas as cores.

Essas duas pressuposições levam-nos a perceber que a dialética que está em jogo aqui é fundamentalmente outra que a hegeliana. Trata-se de uma dialética antidialética, como Nishida mesmo nomeia, de uma dialética que não está baseada no sujeito, que não atinge sua perfeição na concreção do abstrato do sujeito, mas na concreção do sujeito-objeto abstrato-concreto. É que Hegel se apoia em uma perspectiva do 'eu intelectual', ou seja, subjetivo, que age no objeto sem que o objeto esteja agindo também sobre si. Para Nishida, isso é um equívoco: o sujeito age nas coisas e as coisas agem no sujeito: a origem está na matéria e no sujeito, não estando ao mesmo tempo em nenhum deles.

O empenho central de Nishida é elaborar uma lógica alternativa à lógica formal e objetiva, uma lógica que ele chama de 'dialética', mas que é antes uma lógica do paradoxo $[\ldots]$.

Essa lógica [...] não nega nem invalida simplesmente o princípio de contradição; ela o integra e o contém, juntamente com a lógica objetiva que nele se baseia, num plano mais amplo, como uma lógica particular desta 'lógica concreta' (gutaiteki ronri), mais abrangente, que, apesar de ser caracterizada também como 'dialética', tem muitas afinidades com uma lógica do paradoxo de inspiração kierkegaardiana. (Müller, 2009, pp. 153-4)

Portanto, não se trata de um mero jogo de palavras falar em 'sujeito-objeto abstrato-concreto', mas de indicar que não é o sujeito abstrato a origem e o fim do processo dialético, mas um sujeito abstrato que é igualmente já concreto. A suposição que quero fazer aqui é que esse sujeito é o sujeito da medialidade. Antes de seguir na análise de Nishida, quero justificar essa suposição, com o intuito de, ao fim de nosso estudo, poder avaliar melhor em que medida essa pressuposição é coerente e a relação dessa experiência dialética do sujeito medial com o nada absoluto.

\subsection{Dialética antidialética e voz média}

Lebrun ironiza, a partir de Hegel, a ideia 'atual' de que, para superar o pensamento clássico subjetivante, basta superar a divisão sujeito-objeto, ${ }^{3}$ 
afirmando não se tratar senão de uma ilusão, uma falta de lucidez, um escapismo, a tentativa de uma volta à estrutura linguística da voz média ${ }^{4}$ - parece-me mais justo falar em 'estrutura linguística' do que conceito de 'sujeito-objeto', como faz Lebrun, já que conceito é uma palavra oriunda de toda essa tradição que o 'pensamento atual' coloca justamente em questão. Essa ironia não se mostra mais descabida do que em relação à língua japonesa, em que uma experiência sintática de orações sem sujeitos "é o caso normal da língua japonesa" (Elberfeld, 2009, p. 191), embora seja plausível que "[haja] um 'sujeito' pressuposto, mesmo quando ele não figura na sentença" (Elberfeld, 2009, p. 186). Se a voz média grega não exclui o sujeito, mas indica um processo relacional entre sujeito e objeto, tal como os exemplos paradigmáticos de aisthainomai (perceber com os sentidos) e gignomai (tornar-se) indicam (ver Elberfeld, 2009, pp. 183-5), o que se convencionou chamar de voz média japonesa indicaria "a 'espontaneidade de um acontecer, que surge de maneira natural” (Elberfeld, 2009, p. 188) e, "principalmente, a autorreferencialidade no centro da atenção sob a forma de um ocorrer natural" (Elberfeld, 2009, pp. 188-9).

No texto que analisamos, Nishida parece estar se propondo a pensar uma dialética da voz média, uma dialética cujo sujeito 'pressuposto' é o próprio acontecer do verbo. ${ }^{5}$ Nesse caso, não se trata de nenhuma volta mágica ou mística ao arcaísmo grego pré-socrático, mas uma teorização a partir da própria realidade da linguagem japonesa contemporânea. Ele não está se deslocando de lugar ou se refugiando nas profundezas da floresta ou no longínquo Logos grego, mas está pensando a sua própria experiência contemporânea e atual da sua linguagem contra um pensamento oriundo de uma potência colonizadora.

Se Eberfeld radicaliza ainda mais a questão ao afirmar que o próprio pensar e escrever de Nishida são mediais - "Nishida pensa e escreve na voz média"

que Lebrun chama de "pensamento representativo", reconheço a originalidade da sua interpretação de Hegel, ao tê-lo não como baluarte, mas como crítico dessa tradição mainstream da filosofia, e, com isso, de utilizá-lo como uma arma crítica e não tradicionalista contra a 'moda' crítica atual. No entanto, não será possível me aprofundar, neste trabalho, em uma análise comparativa mais profunda a esse respeito: interessava-me apenas criticar um de seus argumentos presentes nesse trecho, a saber, a ideia de que "contornar o pensamento clássico" ocidental seja um "retorno aquém dos conceitos de Sujeito e Objeto". Na tradição que estudamos, poderíamos dizer, trata-se mais de um 'contornar o pensamento exterior de moda' a partir de uma manutenção revisitada e crítica do 'pensamento clássico oriental ou japonês'. É claro que o Japão, para nós, é analogamente tão distante quanto as profundezas da floresta (negra) e o Logos grego, mas é preciso refletir então a respeito desse 'nós', a constituição da 'nossa' identidade, e também se os pensamentos francês, inglês e alemão não seriam análogos e igualmente distantes para esse 'nós'.

4 A voz média é tida como a mais antiga voz grega e, portanto, do mais antigo que podemos voltar das origens de qualquer tradição de pensamento 'nossa'. Ver: Kühner (1955) e Smyth (2010, pp. 390 e ss.).

5 "Nishida parte dessa forma de experiência, e desenvolve um filosofar que se vincula de novo a esse perfazimento 'desprovido de sujeito', no sentido da voz média” (Elberfeld, 2009, p. 191). 
(Elberfeld, 2009, p. 196) -, mesmo que consciente de que a nomenclatura voz média origina-se das línguas europeias, ${ }^{6}$ interessa-me aqui aplicar consistentemente a hipótese de que a filosofia de Nishida seja um esforço de pensar uma dialética, uma lógica, uma estética e uma fenomenologia mediais na leitura do texto em que formula de modo aprofundado sua noção de dialética antidialética em diálogo aprofundado com Hegel. Se lograrmos algum sucesso nessa tarefa, este estará em apontar 1. Que a relação entre a medialidade de Nishida e a sua vontade de elaborar uma lógica "para dar conta do fenômeno religioso em sua raiz, numa experiência anímica" (Müller, 2009, p. 153 $)^{7}$ propõe uma experiência específica de medialidade, que não é totalmente análoga com a grega ou com a que o 'pensamento atual' procura. Para isso, então, é preciso agora acompanhar Nishida na sua tarefa de pensar uma dialética medial, salientando os principais problemas e conceitos que essa tarefa apresenta para o pensamento consequente e qual a função da noção de nada absoluto.

\subsection{Em torno de fundo: mediação e modificação no espaço-tempo da con-} tradição da dialética-antidialética

Ao colocar a questão da autoidentidade e da pluralidade no âmbito da identidade e da continuidade, Nishida afirma que a identidade de uma coisa só se dá na medida em que essa coisa se continua, se medializa e se permeia, ou seja, se modifica: o autoconhecimento de si só pode acontecer na medida em que nesse processo o 'si' já não seja mais o mesmo que o 'auto'. Isso implica uma noção de mediação.

A unidade é sempre mediada e, portanto, em grande medida uma mediação. Mas, se for só mediação, ela nunca seria unidade em sentido forte, pois seria sempre a relação entre duas coisas. Por isso, é preciso que essa mediação seja por si mesma uma unidade, quer dizer, ela mesma é idêntica e total a si mesma, se se compreender esse 'si mesma' também como ambas

6 Cf. Elberfeld (2009, p. 189). "Pertence às ironias da história da linguagem que a voz média, na língua japonesa, permaneça até hoje muito viva; mas sob a influência da escritura gramatical europeia desde o tempo Meiji, quase não é descrita como voz média. No entanto, no uso da língua, a explicação gramatical e a interpretação filosófica se imbricam sem esperança".

7 Müller sugere algo ainda mais agudo, a saber: "Por meio dessa nova lógica Nishida procura, em uma reformulação de conceitos da filosofia ocidental, principalmente da sua linguagem dialética, tais como negação, autonegação, negação da negação, oposição, contradição, um enunciado conceitual mais preciso do pensamento zen-budista" (Müller, 2009, ib.). O que está de acordo com a ideia veiculada no apontamento 1., uma vez que um enunciado conceitual mais preciso do pensamento zen-budista é diferente de um enunciado da cultura grega arcaica ou pré-arcaica. É esta diferença que me interessa salientar aqui, e acredito que o principal aspecto que marca essa diferença resida justamente na noção de nada percorrida durante todo o texto. Vale deixar em dúvida, no entanto, se Nishida tinha em vista unicamente pensar o zen-budismo, ou se ele não ia além dessa que é apenas uma das vertentes históricas orientais da filosofia. 
as coisas mediadas. Isso implica, então, que "a efetiva unidade é algo que nega a si mesma e a si mesma medeia e o efetivo mediado é algo que a si mesmo nega e a si mesmo individualiza. A unidade é um mediado, o mediado é uma unidade" (Nishida, 2011, p. 60). É esse processo que Nishida chama de "autoidentidade contraditória" (ver Nishida, 2011, p. 59) e ele implica justamente uma noção de unidade contraditória, assim como a de um fundo em que a(s) unidade(s) se dá(dão) e que a(s) medeia(m) e individualiza(m).

Esse fundo é espacial e temporal, é circular e linear. A linha são pontes, continuidades, de círculos, que são linhas que continuam infinitamente até se reencontrarem no seu ponto de chegada. Contudo, aqui, essas noções também podem ser entendidas no sentido de que as linhas não são contínuas, porque entre um ponto e outro há sempre algo que não há, e menos ainda o são os círculos, pois são tanto compostos por linhas, como, sendo infinitos os espaços, nunca se chega ao ponto de chegada novamente. A reta é composta de pontos que são círculos, o círculo é uma linha que retornou ao seu ponto de origem. Não surgiu antes o círculo ou a reta, nem o círculo existe sem a linha e vice-versa: ambos estão implicados, sem que estejam totalmente.

Esse fundo é o da presentalidade do presente, na medida em que, para Nishida, tempo e espaço unem-se no presente. Esse não se deixa apreender e se constitui na melhor forma de entender a contradição da autoidentidade. A dialética antidialética é a expressão da experiência do presente, no sentido em que esse presente nunca apreendido é o local em que as coisas se dão uma ao lado e contra as outras. Trata-se de perceber que a realidade se movimenta, i.e., modifica-se e é, ela mesma, unidade contraditória consigo mesma: esse é o significado da passagem do tempo e da espacialidade do tempo. Nishida resume: "uma coisa efetiva[-se], na medida em que nega a si mesma, torna-se outra e como efetivante efetivo retorna para si mesma" (Nishida, 2011, p. 62).

Para Nishida, contudo, esse processo não é nada mais do que o processo da dialética subjetiva hegeliana, uma vez que esta, para ele, se manteria presa à subjetividade. Só a partir da noção de novo e de ato criador é que será possível se desvencilhar do ponto de vista subjetivo. Aqui, a noção de nada absoluto assume papel fundamental.

1.4 A construção de tempo e espaço na dialética antidialética: o novo, o ato criador e o nada absoluto

O novo é constituído nesse processo por meio da autodeterminação do presente. É que essa autodeterminação do presente é a efetivação paralela e uma contra a outra das coisas: é nesse processo que 'se dá' o novo. É isso que significa a autoidentidade do mundo dialético. Autoidentidade do mundo 
dialético é o que Nishida nomeia de 'kuseisarô', i.e., ato configurador. Esse ato configurador é criativo (schöpferisch), mas ele determina, ao criar, sem que haja um determinante, ou seja, um sujeito ou uma identidade que organiza a experiência. Mas também não é criador no sentido de que as coisas são produzidas do nada, conquanto no sentido de que "coisas incontáveis se determinam umas às outras e efetivam-se umas às outras igualmente" (Nishida, 2011, p. 63). Na verdade, essa criação é o que garante que não vivemos num mundo do retorno do sempre igual, que Nishida chama de mundo da ciência - limitado por não ser capaz de lidar com o que está fora do padrão ou do previsível -, da sua regularidade e ordinariedade: esse 'novo' dá conta do processo da vida, na medida em que esse processo é contínuo-descontínuo. ${ }^{8}$ Vida é o que Nishida chama de mundo histórico ou mundo da realidade. Ele afirma que esse mundo, o mundo da criação, é o "mundo da determinação do nada, i.e. da determinação sem determinante" (Nishida, 2011, p. 63, grifo nosso). Ele diz entender esse mundo como o do eterno agora, no qual o linear é circular e o circular linear. Esse é o mundo prático, pode-se dizer, extraordinariamente ordinário, poiético espaço-temporal, subjetivo-objetivo e isso significa, em suas palavras, "uma modificação do comportamento no mundo subjetivoobjetivo, expressivo, i.e. no mundo histórico-social” (Nishida, 2011, p. 65). Todos esses nomes para mundo prático que Nishida dá no decorrer de seu texto não são nada mais, parece-me, do que uma tentativa de interpretar a noção de samsāra. E é interessante lembrar que o retorno a este mundo é um dos passos fundamentais do caminho de iluminação budista, tal como se passa no texto de Nishida. De certa forma, vai se percebendo que os passos teórico-argumentativos de Nishida seguem os da argumentação budista, e que sua atividade constitui-se numa comparação crítica e aprofundada entre as possibilidades de ambas as tradições.

Isso significa, então, que o modo de sair do mundo subjetivo é, para Nishida, cair no mundo da prática por meio de um ato criativo em que o novo surge de uma determinação do nada. Esse ato criativo é chamado por Nishida de poiético e é expressivo, não no sentido de uma criação ex nihilo, mas no

8 Seria interessante aproximar essas noções de uma análise filosófica da obra O Mestre e a Margarida, de Bulgakov, enquanto o ponto culminante e final da tradição moderna do romance russo, a qual flerta igualmente com uma crítica ao ocidentalismo em nome nem tanto de um irracional, mas de uma afirmação dos limites do racionalismo. Ali, a crítica de Woland-demônio ao chefe da MASSOLIT, Berlioz, que encarna a ideologia socialista materialista oficial da década de 1930 na União Soviética, diz respeito justamente à incapacidade de se prever o futuro, porque nele sempre há algo de imprevisível para o homem. É essa imprevisibilidade que pode ocorrer que garante a ficção de Bulgakov, e que aqui terá consequências religiosas que iremos abordar. Obviamente esse trabalho excede as intenções deste estudo, mas a sua indicação instaura o âmbito e aponta o horizonte de relevância da análise aqui realizada. 
de que as coisas se dão muito mais porque a determinação do singular é uma determinação do nada, na medida em que esse singular não existe enquanto singular em sentido forte. O nada é o que permite o novo, mas não como seu fundo, conquanto como o fundamento da unidade e da pluralidade. Nas palavras de Nishida, como o lugar contínuo-descontínuo. É só na medida em que as coisas não são elas mesmas e sim, "no fundo", nada, que pode haver o novo, ou seja, em que saímos do subjetivo-objetivo e caímos no mundo do comércio, da prática, ao mesmo 'tempo' um mundo poiético e expressivo (ausdrücklich) no sentido linguístico.

\subsection{A tarefa de Nishida de adaptar contemporaneamente a dialética a um} pensamento medial

A partir disto analiso apenas mais um aspecto do texto de Nishida, Autoidentidade e continuidade do mundo, em que parece que Nishida está se propondo adaptar a dialética a um pensamento medial, da voz média, uma dialética cujo sujeito 'pressuposto' é o próprio acontecer do verbo. Nesse caso, e ao longo de toda a sua obra, não se trata de nenhuma volta mágica ou mística ao arcaísmo grego pré-socrático, mas uma filosofia erguida a partir da própria realidade da linguagem japonesa contemporânea. Isso por si só não garante a validade do que está dizendo, assim como ser interno à tradição ocidental também não garante nada à dialética hegeliana, mas garante que seja necessário darmos voz a seu pensamento, justamente porque neste campo ainda nada está resolvido.

$\mathrm{O}$ aspecto que eu queria salientar é a argumentação de Nishida que visa defender que uma coisa só pode ser idêntica a si mesma se for na verdade um termo medial entre outras coisas. Segundo Nishida, a autoidentidade de uma coisa, ou seja, o fato de uma coisa ser uma coisa, ocorre apenas como um processo: uma coisa nunca é meramente uma coisa, mas se torna uma coisa modificando-se e ao mesmo tempo não se modificando. Só posso dizer, com isso, que uma coisa é uma coisa na medida em que ela, sendo múltipla, é unitária. Para Nishida trata-se, portanto, de expor essa contradição de identidade: o múltiplo é múltiplo de unidades, a unidade é unidade de multiplicidade.

A unidade só pode ser entendida nesse caso como sempre mediada e, portanto, em grande medida, uma mediação. Mas, se for só mediação, ela nunca seria unidade em sentido forte, pois seria sempre a relação entre duas coisas. Por isso, é preciso que essa mediação seja por si mesma uma unidade, quer dizer, ela mesma é idêntica e total a si mesma, se se compreender esse 'si mesma' também como ambas as coisas mediadas. Isso implica, então, que "a 
efetiva unidade é algo que nega a si mesma e a si mesma medeia e o efetivo mediado é algo que a si mesmo nega e a si mesmo individualiza. A unidade é um mediado, o mediado é uma unidade" (Nishida, 2011, p. 60). É esse processo que Nishida chama de 'autoidentidade contraditória' (ver Nishida, 2011, p. 59) e ele implica justamente uma noção de unidade contraditória, assim como a de um fundo em que a(s) unidade(s) se dá(dão) e que a(s) medeia $(\mathrm{m})$ e individualiza $(\mathrm{m})$.

Esse fundo é o que ele chama de lugar do nada absoluto. O lugar do nada absoluto é chamado por Nishida de presentalidade do presente, na medida em que, para Nishida, é a união de tempo e espaço no presente, que é atemporal, porque sempre presente, porque vivenciado sempre previamente pelo sujeito. Mesmo a lembrança do passado, a expectativa do futuro ou a cotidianidade do presente encontram-se em um presente que a cada vez sempre está sendo aqui e agora. Esse presente originário não se deixa apreender nem mesmo pelo pensamento, porque ele é contraditório em si mesmo. Pensemos assim: se a dialética antidialética é, para Nishida, a expressão da experiência do presente, no sentido de que esse presente nunca apreendido é o local em que as coisas se dão uma ao lado e contra as outras, é preciso ver que a realidade movimenta-se, modifica-se, e possui, ela mesma, uma unidade contraditória consigo mesma. Em outras palavras e grosso modo, para a perspectiva que deve bastante ao zenbudismo de Nishida a experiência medial da linguagem japonesa só pode ser compreendida a partir de um fundamento que é contraditório em si mesmo, o nada absoluto, porque enquanto fundamento não é nenhum fundamento, sendo justamente um fundamento na medida em que não é nenhum fundamento.

Ocorre que é preciso questionar-se se o nada absoluto, uma reinterpretação original de Nishida da antiga tradição zen-budista, é o que de fato fundamenta ou explica a experiência medial da linguagem japonesa, ou se não é, em nome de uma crítica apropriativa da filosofia ocidental, uma tentativa ao mesmo tempo de colonizar essa mesma experiência, i.e., da linguagem japonesa. Mesmo que seja, não é em vão se debruçar na tentativa mais proeminente da época de buscar desenvolver uma filosofia em diálogo entre o Ocidente e o Oriente, e de apontar para o fim dessa dicotomia.

Em outras palavras: pode muito bem ser que Nishida esteja comprometido em problematizar a filosofia a partir da experiência medial presente no cotidiano da língua japonesa, mas isso não quer dizer que a medialidade japonesa esteja baseada, mesmo que contraditoriamente, apenas na noção budista de nada absoluto. Seria preciso traçar, como Nietzsche, a genealogia da voz média japonesa, e, com isso, acredito, veríamos a sua complexidade. 


\section{Circunstar nada: o nada em Ueda e Nishitani entre o dizer e o calar}

Nesta sessão quero analisar um texto de um momento posterior ao de Nishida e que também é considerado pertencente à Escola de Kyoto, a fim de no final desta análise compará-lo, por um lado, retrospectivamente, com o texto de Nishida analisado e, por outro, com o de Tsujimura, para mostrar dois caminhos do desenvolvimento do nada absoluto dentro da própria Escola de Kyoto. O texto de Nishida é uma amostra significativa do que é considerado o nascimento da Escola de Kyoto. De uma certa forma, espera-se, as próximas gerações, para serem designadas como pertencentes à Escola de Kyoto devem ser seus 'discípulos', e, neste caso, isso é entendido como aqueles que realizam seu trabalho no espaço cinzento entre a tradição filosófica ocidental e a oriental. No entanto, não basta apenas isso para ser considerado um autor da Escola de Kyoto, do ponto de vista teórico: é preciso ainda que esse aporte de filosofia comparativa se dê tendo em vista discutir e aprofundar a questão do nada. Em outras palavras, o nada absoluto deve ser um dos conceitos centrais da atividade filosófica dos autores que visam adentrar nesse campo das possibilidades de comparar e conjugar as tradições filosóficas ocidentais e orientais.

A partir dessa complexidade deste início de uma tentativa única de renovação da tradição oriental em uma relação instigante com a filosofia ocidental, prosseguiremos nosso estudo, dando um salto histórico para o estudo do texto de Ueda $O$ nada absoluto no Zen em Eckhart e em Nietzsche. Este ganha em interesse se observado como uma máquina de guerra filosófica, no sentido de que é uma tentativa bem clara de marcar um lugar próprio para a tradição zen-budista no que concerne à discussão em torno do nada absoluto. Se os interlocutores ocidentais de Nishida eram principalmente Hegel, Kant, neokantianos como Vahinger, James, entre outros, Ueda neste texto, que os editores fazem questão de dizer que se constitui um exemplo dos esforços filosóficos que empreendeu durante sua vida, está dialogando diretamente com aqueles autores ocidentais que - pertençam eles aos cânones ou estejam marginalizados - tiveram alguma preocupação em se aprofundar no conceito de nada. Neste caso, trata-se de Eckhart e Nietzsche. Se hoje observamos algum tipo de renascimento do misticismo e do neoplatonismo nos estudos de filosofia acadêmica no Ocidente, isso só pode estar diretamente relacionado também à reabertura dos estudos de filosofia oriental na Europa e no resto do mundo ocidental, na medida em que esses fenômenos, conjugados, podem ser vistos como uma espécie de terceira grande abertura do Ocidente ou de renascimento. Nesse sentido, poder-se-ia pensar o esgotamento do projeto da modernidade como o esgotamento do projeto do segundo renascimento, o 
romântico, e uma reabertura reincorporante, tanto de uma tradição esquecida (desde uma nova interpretação dos pré-socráticos em Nietzsche e Heidegger, até os novos estudos sobre Plotino, Próclus, Pirrônicos, a noção de paresia etc. realizada por uma série de autores) $;{ }^{9}$ como do mundo filosófico oriental. Ao aproximar, então, dois autores ocidentais que se debruçaram sobre a noção de nada, Ueda está interessado em dar um lugar próprio ao budismo no interior da filosofia, assim como está, de modo antes nunca realizado, abrindo caminho para a relação entre essas duas grandes tradições.

Este texto se insere no gênero da filosofia comparativa. Comparar significa colocar ao lado de. O que Ueda faz é colocar a filosofia oriental, ou mais especificamente o budismo zen, como modelo ou parâmetro, de modo a discutir em que medida a filosofia ocidental se aproxima desse modelo. Ocorre que uma comparação exige que os dois (ou mais) lados sejam comparados um em relação ao outro e vice-versa. Nesse sentido, pode-se afirmar que o texto de Ueda constitui-se apenas de um momento do desenvolvimento da filosofia comparativa, que deve, no entanto, ser aprofundado. Justifica-se essa atitude de Ueda pelo contexto histórico: seu intuito estava principalmente em diferenciar o zen-budismo de algumas filosofias ocidentais que num lugar comum poderiam se aproximar ou se identificar com o budismo, a fim de prover-lhe um lugar próprio nas filosofias a ser estudadas por si mesmas.

É interessante ressaltar os momentos históricos distintos, o que significa preocupações e contextos completamente heterogêneos em que tais autores estão inseridos. Por trás desse procedimento de Ueda, está clara a intenção de mostrar tanto que, em relação ao nada absoluto, a tradição ocidental se desenvolveu por desvios de rota, por lampejos, por momentos não constitutivos dos cânones: essa tentativa de dar lugar ao zen-budismo também acaba por dar lugar a esses autores ocidentais. Também pode ser atribuído a tal procedimento o fato de que o nada zen-budista pode ser comparado não apenas com a filosofia mística e não apenas com a crise da filosofia moderna, mas com qualquer um destes momentos da filosofia ocidental (e talvez outros, mas aqui se concentra em ambos os autores).

$\mathrm{O}$ expediente de Ueda neste texto reside em argumentar que Eckhart e Nietzsche desenvolvem seus conceitos de nada, no entanto, não avançam nas consequências dessa noção como faz o budismo, de modo que acabam sendo duas faces de um momento do nada absoluto zen-budista. Em outras

9 É interessante perceber que esses autores reencontrados versam sobretudo a respeito do esgotamento da cultura grega no fim da Antiguidade, ou possuem suas raízes em tradições "bárbaras", i.e., não exclusivamente gregas, como é o caso da filosofia japonesa aqui estudada. 
palavras, trata-se de dizer que é possível enquadrar (literalmente) alguns desenvolvimentos do conceito de nada na tradição ocidental na própria teoria budista, a qual deteria uma noção mais fundamental de nada que a Escola de Kyoto, por conta de Nishida, chamada de nada absoluto.

Ele assim o faz comparando as filosofias desses dois autores a um texto zen-budista do século XII intitulado "O Boi e seu Pastor. Uma antiga história zen". Trata-se da exemplificação didática dos passos que o homem que procura por si mesmo deve dar em seu caminho. Ueda explica, casa a casa, o significado desses passos que as casas apontam. Seu fazer pode ser compreendido, no limite, como o de didaticamente mostrar ao Ocidente até que ponto do ensinamento zen eles teriam chegado. Parece que, para ele, Eckhart e Nietzsche teriam sido os alunos ocidentais mais prodigiosos do Zen. Mas haveria algo que o zen-budismo poderia aprender com o Ocidente? E haveria algo que nem 'ocidente' nem 'oriente' teriam aprendido?

O nada é absoluto aqui no sentido de que ele é a peça padrão, o modelo ao qual aproximaremos as outras noções de nada. É verdade que se trata de algo em alguma medida necessário, enquanto presta esclarecimento das diferenças e busca diminuir o preconceito que o budismo em tal contexto histórico sofria. Era preciso diferenciá-lo do ápice do misticismo e do 'niilismo' ocidental. O budismo, com isso, visa assumir uma posição única na filosofia. A crítica que se pode fazer, no entanto, é que é preciso que também o budismo não seja visto como parâmetro, que ele também seja passível de crítica. É que ele não pode ser visto como a doutrina última à qual as outras devem se adequar. "Escola" não pode ser visto como uma escola dogmática, mas como um espaço de reunião em que as questões ali postas estão longe de se esgotar.

\section{Quem sou eu em dez quadros}

Boi é um símbolo comum para o verdadeiro eu procurado, ou seja, para a autoidentidade, e pastor representa o homem que se preocupa com o verdadeiro eu. Deve-se notar que 'quem sou eu?' é a questão de fundo aqui. Do mesmo modo que em Kant as quatro questões metafísicas podem ser resumidas na questão 'quem é o homem?', a tradição budista resume as questões filosóficas (de onde viemos?, para onde vamos?...) na questão 'quem sou eu', também presente na tradição ocidental, desde seu arquétipo edipiano e que em Ser e Tempo assume o esgotamento do projeto (neo)kantiano e uma abertura para um possível diálogo a partir da tradição ocidental, com o Oriente (ver §31 de Ser e Tempo). A exaltação conheça-te a ti mesmo é a estrutura da tragédia, que se constitui como tal graças ao modo como Édipo procura obstinadamente as respostas. Não é a busca pelo autoconhecimento que é trágica, mas esta tal 
como é executada por Édipo, i.e., de modo obstinado, radical e em busca de certeza e exatidão. No texto chinês, não se trata de tragédia. O caminho dessa busca é nele representado em dez estações. Da primeira à sexta é representada a busca e o encontro do pastor com o boi e a volta para casa sobre o animal. A sétima chama-se "o boi foi esquecido, o pastor se mantém". A oitava estação chama-se "esquecimento perfeito do pastor e do boi" ou "esquecimento duplo" e é representada por um círculo vazio.

No quadro, esse círculo representa o nada absoluto. Esse nada absoluto não quer dizer que não haveria nada. Trata-se muito mais da necessidade do homem de se libertar do pensamento substancializante e da autodefinição substancializante: esquecer-se a si mesmo é a sua tarefa. Para o budismo, afirma Ueda, no pensamento substancializante reside a origem da substancialização do homem, a qual é uma raiz oculta do aprisionamento [Verhaftheit] do eu. É preciso esquecê-lo. Ao substancializar o ser na tentativa de conhecê-lo e determiná-lo, o homem substancializa-se a si mesmo. Responder à questão 'quem sou eu?' é, para o pensamento substancializante, afirmar a consciência de eu como "eu sou eu", de modo que "eu sou eu, porque eu sou eu". Eu sou eu, porque eu sou eu: o homem é aquele que de manhã tem quatro pernas, de tarde duas e ao anoitecer três, porque eu (Édipo) sou (este) homem. Isso seria a definição que substancializa, pois aprisiona o eu em si mesmo pelo princípio de identidade. $\mathrm{O}$ verdadeiro eu do budista, a que se deve chegar na casa 8, é, no entanto, diz Ueda citando Nishitani, "eu sou eu, e ao mesmo tempo eu não sou eu”, ou citando Suzuki, “eu sou eu, porque eu não sou eu” (Ueda, 2011a, pp. 441-2). A definição do eu é descontinuamente contínua. Ela está entre a identidade de Parmênides e o constante devir de Heráclito, e não se apoia em uma teoria das formas de Platão que intensifica a substancialização ao negar a possibilidade de se pensar o nada. Ao contrário, talvez, do que outras vertentes budistas afirmariam, aqui a afirmação que surge da negação é valorizada; mas esse 'eu' que é afirmado ao ser negado, não pode ser nenhum eu em sentido forte e talvez seja nisso que resida a peculiaridade da medialidade que esse tipo de lógica propõe: não é que é negado o sujeito, conquanto muito mais que ele está lá, mas não sobrevalorizado.

A representação do círculo como nada absoluto parece querer que se dê ênfase à diferença fundo-traço que nela surge. O nada absoluto não é nem só fundo, nem é o círculo enquanto tal. Ele é o círculo que é fundo que é círculo. Em outras palavras, pode-se dizer círculo que não finda, mas a representação para dar conta dessa ideia precisou desenhar um círculo e, além dele, nada. Há um eu que ao mesmo tempo não sou eu, o círculo se descontinua do fundo, sendo a sua própria continuidade. 


\section{Nietzsche, Eckhart e o nada absoluto}

Para Ueda, tanto Nietzsche quanto Eckhart seriam os expoentes da filosofia ocidental que teriam chegado até à casa oitava.

A afirmação de Eckhart de que 'Deus é nada' significa que Deus é nada para as palavras do homem, e nesse sentido é tudo, porque as palavras do homem são nada. Assim, 'nada' é visto como um adjetivo da suma substância, na medida em que ser nada é abarcar o todo das possibilidades de ser. No zenbudismo, contudo, argumenta Ueda, o nada é verbalizado, negando o caráter de substância de Deus.

O nada absoluto do Zen, em seu caráter puro e simples, tem como tal uma atmosfera diferente do 'Deus é nada'. [...] Não se trata de 'Deus é', não é 'Deus é nada' e também não é 'Deus não é'. Trata-se da dissolução da substancialidade que, como tal, conduz a afirmação 'Deus é...'. [...] Nesse sentido, o nada não é, aqui, um adjetivo do 'um' como substância, ao contrário, ele tem que ser verbo. Enquanto que a substancialidade se esvazia e o 'lugar do nada' se inicia no vazio, ela dissolve o 'um' substancial no vazio, no 'lugar do nada', ela deixa o um se tornar o diverso inesgotável [...] (Ueda, 2008, p. 221)

Fica a questão se a filosofia de Eckhart pode ser vista como puramente uma filosofia da teologia negativa e se, mesmo que não possa ser vista, isso invalida os argumentos de Ueda.

Disso, Ueda vê Nietzsche como o polo negativo do nada absoluto. É assim que ele compreende a frase de Nietzsche 'Deus está morto'. Nietzsche é para ele a profunda negação da substância, mas sem nenhuma positividade, pelo contrário: o que ele faz, diz Ueda, seguindo (ou ao menos aparentemente) a interpretação heideggeriana de Nietzsche, é substancializar a vontade de poder.

Mas o movimento do niilismo que Nietzsche de fato desenvolveu tornou-se um movimento que encontrou sua força propulsora na 'vontade'. [...] Essa vontade é mantida no ressaltar da forma pura e originária da vida, como da 'vontade de vontade' (de acordo com Heidegger), mesmo como 'vontade de poder', e esta 'vontade de poder' se transforma no elemento superador do niilismo como força motora do niilismo ativo e positivo. (Ueda, 2008, p. 229)

Ele só remete à autoexpressão direta de vida pura quando se aproxima de Heráclito, e diminui a importância do poder (aqui talvez possam se entrever as diferenças da sua interpretação em relação à de Heidegger), dando ênfase ao brincar e ao esquecer-se presente no jogo.

Parece que a ideia 'esquecer = brincar' tem uma ligação direta com o caminho do 'sem porquê', mencionado há pouco, e sua afirmação, vista a partir da superação 
do niilismo, mostra um parentesco próximo com o Zen. [...] Mas parece que para Nietzsche esta relação entre nihil, vontade de poder e criança ainda não teria sido, de maneira totalmente clara, consciente. (Ueda, 2008, p. 233)

Aqui, fica ainda a se saber se a interpretação de que Nietzsche permanece em um caráter negativo da negação é suficientemente justa com a letra de Nietzsche. A suspeita é de que não, também porque é suspeito que Eckhart e Nietzsche se complementem em relação aos aspectos do nada absoluto.

A sua crítica a ambos os pensadores consiste em que eles não deram o passo seguinte, voltando ao mundo da vida, ou, como diz o próprio título da $9^{a}$ casa, "as flores florescem como florescem por si mesmas; o rio corre como corre por si mesmo". Quer dizer, trata-se de voltar ao mundo como o mundo por si mesmo é. Do ponto de vista do 'eu', trata-se de, ao negá-lo, afirmálo como ele é. Diz-se que, em um ensinamento zen, dizia-se que, antes da iluminação, as árvores eram árvores, os rios eram rios, as montanhas eram montanhas; durante a iluminação (que poderíamos entender como a casa $8^{\mathrm{a}}$ ), as árvores não eram árvores, os rios não eram rios, as montanhas não eram montanhas; após a iluminação (casa $9^{\mathrm{a}}$ ), as árvores são árvores, os rios são rios, as montanhas são montanhas. É essa volta ao mundo vivido (ao saṃsāra), ou, em outras palavras, à completa identificação da verdade de samsā̄ra e de nirvana, o que, para Ueda, não estaria presente nesses pensadores ocidentais. Ele diz:

Por parte da afirmação absoluta, o nada absoluto é congruente com o 'nada absoluto' positivo de Eckhart, por parte da negação absoluta ele é congruente com o "nada absoluto' negativo do niilismo radical. Porém, visto que a correspondência das pessoas e o entrelaçamento das pessoas, da negação absoluta e da afirmação absoluta sejam o nada absoluto - e isto é exatamente o movimento do 'nada do nada' -, tem-se então que, por um lado, em Eckhart, a negatividade não foi levada avante suficientemente, e, por outro lado, falta negatividade a Nietzsche. O nada absoluto, permanece, em ambos, negativo. (Ueda, 2008, p. 234)

O texto todo parece assumir um caráter pedagógico, como o do mestre zen que dá indicações de procedência para seu discípulo, a filosofia ocidental, de como prosseguir no seu caminho no desenvolvimento de sua identidade consigo mesmo. O zen-budismo permanece como inquestionado e doutrina absoluta. Se é interessante ressaltar o que essa teoria tem a acrescentar às outras, valeria a pena também perceber se não há nada que as outras poderiam acrescentar ao zen-budismo, até mesmo no sentido de uma perspectiva própria e livre, a qual nenhum desses autores ou correntes de pensamento teriam alcançado. Em filosofia, não se trata de chegar ao cume da montanha e depois voltar, pois até mesmo o que são o cume e a montanha está em questão. Será 
que esse caráter doutrinário do zen-budismo neste texto não seria criticado por esses dois autores? É sabido o caráter de crítica social presente em muitos místicos, assim como também fazem parte dessa determinação alguns expoentes do budismo, seja o próprio Sidharta, ou até mesmo, por exemplo, Nāgārjuna. É que, fazendo desta forma, Ueda transforma o zen-budismo em uma doutrina, um método, e talvez justamente aí perde sua força crítica em relação a esses dois autores, ambos críticos do status quo (ambos em seu modo, também não se deve exagerar a marginalidade dos dois). Ressalva-se apenas que, mesmo dentro do ambiente japonês filosófico do século $\mathrm{XX}$, os autores da Escola de Kyoto foram bastante criticados, sobre o que Zavala discorre em Tres críticas a la Nada absoluta de Nishida Kitarô 1926-1935 (Jacinto Zavala, 2013). Em outras palavras, sente-se falta de um não apego à sua própria doutrina e aos esquemas e sistemas mentais próprios - por exemplo, a associação de Eckhart e Nietzsche aos polos positivos e negativos do nada absoluto budista nunca foi fundamentalmente colocada em questão nesse texto -, e uma capacidade crítica mais dinâmica que talvez Nietzsche ou um certo nietzschianismo poderiam ser absorvidos pelo pensamento japonês.

Quanto à noção de nada absoluto de Ueda, a partir deste seu procedimento, vê-se, acaba por assumir uma de suas principais características: ele não é um conceito absoluto, mas um desenvolvimento, não em sentido hegeliano, mas no de que ele possui características diferentes conforme o momento da exegese argumentativa. Quer dizer, o nada absoluto é isto ou aquilo conforme o contexto. Isto, é verdade, já está presente na tradição budista, quando ela discute os dois (ou três) tipo de verdade. Essa característica do nada absoluto é muito interessante, porque se trata de um conceito que só pode ser compreendido em seus momentos temporais, quer dizer, ele perpassa a negação e a afirmação de si mesmo.

Tal temporalidade do conceito de nada absoluto pode ser vista sob um segundo aspecto, o da extrapolação da linguagem. Em outras palavras, a sua compreensão só pode se dar por meio de uma compreensão que extravasa a linguagem, na medida em que é o próprio homem existencialmente que precisa compreendê-lo. Zavala chama isso de "vivência do nada absoluto". Essa 'ainda não' separação entre o homem prático e o homem contemplativo assume, nesse momento da discussão da filosofia no século XX -em que ainda não se decidiu de que maneira a teoria deve levar à prática - uma força que em outro momento teria sido vista como uma fraqueza. 


\section{Nishida entre Ueda e Tsujimuri}

Ueda analisa o nada de Eckhart como um nada que é a suma afirmação positiva dos atributos de Deus. Na teologia negativa, na qual Ueda insere Eckhart sem grandes considerações a respeito, Deus é nada na perspectiva humana, que é finita, e, portanto, é tudo. Em contrapartida, a não existência de Deus enunciada por Zaratustra é interpretada por Ueda em matizes heideggerianos (ao menos sob um primeiro olhar), como a não existência do mundo das razões superiores. Ora, isso não passa, para Ueda, do anúncio da suma inexistência de Deus. Ao colocar as filosofias de Eckhart e Nietzsche deste modo, Ueda quer mostrar como tanto Eckhart quanto Nietzsche permanecem no conceito de nada como sujeito, como nome, como substantivo, enquanto o nada absoluto da tradição zen budista está no âmbito verbal, na relação com ser e não com Deus.

É claro que isso só pode ser dito sob um excesso de reducionismo de ambos os autores ocidentais analisados na esteira de uma outra redução realizada por Heidegger. Embora isso deva ficar claro, o ponto que quero tratar aqui é o de compreender um momento fundamental do fortalecimento da filosofia japonesa, percebendo com isso seus pressupostos, preconceitos e valores. $\mathrm{O}$ texto aqui analisado é rico nesse sentido.

Já indicamos dois pontos básicos desse nada, e aqui quero seguir um pouco adiante, discutindo a relação deste texto com o de Nishida. Com a comparação e início de diálogo com conceitos ocidentais diferentes dos com que Nishida discute, nosso circunvolver encontra aí já algumas diferenças de caminho. Ele não se vale tanto da contradição, uma vez que os autores com quem dialoga também não fazem caso da dialética. Com isso, Ueda enriquece o trabalho de Nishida. A negação da negação em Eckhart não é dialética em sentido hegeliano ou anti-hegeliano (contradição anticontraditória), quer dizer, não é a contraposição contraditória de dois termos. No entanto, a conclusão de Ueda de que o nada é verbal, acaba aproximando-o de Nishida novamente, assim como é possível ouvir em sua crítica à teologia negativa que atribui a Eckhart a ideia da imanência transcendente de Nishida, enquanto Eckhart ficaria na transcendência ou imanência de Deus. Ou seja, aproximando nesses termos de Nishida a ideia de Ueda de que Eckhart permanece afirmando a suma substância, vemos que o que há por trás de ambos os autores da Escola de Kyoto é a mesma noção de nada absoluto, no entanto, estando ressaltados aspectos diferentes dessa noção, acabam se formando já pequenos rasgos ou relevos levemente alterados nessas tendências.

Uma dessas diferenças está na ênfase que Ueda dá ao jogo e esquecimento durante o jogar da criança em Nietzsche, enquanto Nishida ressalta a produção 
do mundo histórico. Nesse sentido, haveria uma tendência a valorizar o criar ('artístico'), enquanto em outro o atuar no puro presente. Em certo sentido, são a mesma coisa; em outro, já vão se vendo algumas diferenças que podem, ao longo do tempo, se constituir rasgos fundamentais. A intenção aqui é analisar em que medida Ueda valoriza um ponto outro do nada absoluto. Não quero com essa análise absolutizar essas diferenças, mas apenas indicar possíveis momentos de não convergência entre esses dois autores da mesma escola.

Em um primeiro momento, é preciso apontar alguns aspectos da grande proximidade que há entre ambos. O que está sendo buscado aqui é mostrar como o pequeno deslocamento de conceitos realizados por Ueda e Tsujimura os leva a seguir por caminhos que quase se opõem e que poderiam refletir o próprio momento do desenvolvimento histórico das filosofias ocidentais.

Em nosso circunvolver do nada que fazemos, aproximamo-nos de uma vertente argumentativa que valoriza o nada absoluto como uma vivência por meio do dizer não dizente do que não-pode-ser-dito. Nosso caminhar por este campo nos levará a uma outra região deste mesmo nada, na qual este só poderá ser se se abandonar a linguagem. Em contrapartida, não nos será possível exagerar nas tintas dessa contraposição: Ueda reconhece, na casa 8 , o momento da suspensão de linguagem, o qual, na verdade, deve ser o mais breve possível. O que reivindicamos está antes em uma maior ênfase no poder da linguagem, ou, dito de outro modo, tanto na possibilidade de uma lógica includente de compreender o lugar do nada absoluto, quanto na importância da linguagem em detrimento desse momento - breve - da suspensão do Logos .

A negação que ao mesmo tempo é afirmação que caracteriza o lugar do nada absoluto pode ter um paralelo com a passagem da casa $8^{\text {a }}$ para a $9^{\text {a }}$ do texto zen analisado por Ueda e na relação entre a suma negação e afirmação do conceito de nada de Eckhart e Nietzsche. O extremo vazio deve levar a uma volta do homem ao mundo da vida prática, assim como o nada não é a suma negação da substância em Nietzsche, nem a suma afirmação da mesma em Eckhart. Sendo um meio termo que ressalta o nadificar, aproxima-se justamente da relação do pensamento de Nishida com a medialidade.

$\mathrm{Na}$ mesma esteira de Ueda, Tsujimura possui um estudo de filosofia comparada entre o nada absoluto e as filosofias ocidentais. Assim como Ueda citou Nishida como seu professor, sempre para explicar seus posicionamentos, Tsujimura também o faz principalmente com o próprio Ueda. No entanto, a despeito dessas citações, sua interpretação do nada absoluto, mesmo que aparentemente consonante, é, levada às últimas consequências, bastante antagônica à de Ueda. 
Nada absoluto, ser e verdade em Tsujimura leitor de Heidegger

$\mathrm{O}$ texto que irei analisar é o $A$ verdade do ser e o nada absoluto, que nada mais é do que a conclusão de uma obra maior, o A questão do ser e o nada absoluto. Nesta última sessão da sua obra, Tsujimura compara a verdade do ser em Heidegger (principalmente em seus cursos sobre a poesia, sobre Nietzsche e Heráclito) e o nada absoluto que ele identifica como o rosto originário do Selbst (em Nishida traduzimos por 'auto' ou por 'mesmo', em inglês, dir-se-ia self) para o autoiluminado, ou seja, diz ele, para a verdade do zen.

Tsujimura acredita que ambas as verdades se aproximam nos seus não pertencimentos à metafísica, na medida em que se pretendem a um outro começo. A questão sobre a qual irá se debruçar será, então, se o 'outro começo' da verdade do ser é o mesmo 'outro começo' da verdade do zen. É na tentativa de diferenciar esses outros começos que ele acaba se diferenciando também de Ueda.

É que se a verdade do ser tem que ser trazida à linguagem por meio do pensar e da linguagem, e, ao fazer isso, torna-se 'a verdade', mas entificada, não mais do ser, o nada absoluto surge ali, onde Selbst (o "auto"), mundo e história unificam-se como uma grande dúvida e, diz Tsujimura, onde esta termina, i.e., onde o pensamento 'perde' ou se livra da linguagem, é precisamente onde a verdade do zen é apropriada. Tsujimura afirma que esta é a verdade que não pode ser alcançada com nenhum pensamento e em si mesma não pode ser usada com nenhuma linguagem para atingir a linguagem. Para ele, o momento em que o nada absoluto é chamado de ser e nada, a coisa (Sache), i.e., essa tal verdade do zen, já está bem distante (Tsujimura, 2011, p. 416). É só quando a linguagem chega integralmente ao fim e torna-se nada que essa coisa chega. Portanto, segundo Tsujimura, a verdade do zen é aquela que está sempre antes da linguagem e que não pode ser compartilhada pela linguagem (Tsujimura, 2011, p. 416). Consequentemente, para ele, as duas verdades são originalmente distintas, embora com consequências parecidas, na medida em que a distinção de ambas consiste na diferença entre o pensar que contém a linguagem (a verdade do ser) e a origem do pensar (a verdade do zen) (Tsujimura, 2011, p. 416). Desse modo, ela não significa que seja duas verdades distintas que pertencem à mesma dimensão, conquanto, para ele, trata-se principalmente do fato de que cada uma, enquanto verdade, instaura as suas próprias dimensões.

A partir daí, Tsujimura analisa em que consistem as diferenças do que ele chama de dimensões. Em primeiro lugar, a diferença de dimensão presente entre essas duas verdades também se aplica à diferença entre estas e a metafísica. Assim, se a questão do ser é oriunda de um âmbito metafísico, 
ela instaura, em sua estrutura, a memória de um outro início em relação à metafísica. Para Tsujimura, então, a questão do ser estaria entre o pensamento e a origem do pensamento: é isso o que para ele o aí de ser-aí significa. Aqui, fica a questão de como Tsujimura compreende o '-' de ser'-'aí: não seria este, mais do que a dimensão da finitude do ser - o ' $d a$ ' -, o entre do pensamento da diferença ontológica de Heidegger?

Tsujimura pensa os âmbitos de tais verdades do seguinte modo: a verdade do zen estaria na origem a partir de onde pensamento e linguagem são possíveis, pois, segundo ele, a verdade do zen não se deixa abarcar pela linguagem e pelo pensamento, mas, na verdade, os abarca; já a verdade do ser seria aquele âmbito entre a verdade do zen que não pode ser dita e a verdade da metafísica como linguagem dos dois lados - uma espécie de terceira margem do rio entre a origem do pensamento e o pensamento, ou, segundo a imagem tradicional da filosofia como base da árvore do conhecimento (Tsujimura, 2011, p. 419), mobilizado por Heidegger em seu $O$ que é a metafísica?, entre a árvore e o seu entorno, quer dizer, aquilo, entre a totalidade dos entes e o nada, que é o que está além daquele.

Em seguida, Tsujimura avalia que a diferença de dimensões em que essas verdades possuem validade consiste mais do que tudo em uma diferença no modo de comportamento em relação ao pensamento e à linguagem. Para ele, a diferença constitui-se em que a verdade do ser acontece no pensamento do que a cada vez não é possível ser pensado, ou seja, daquilo que pertence antes do próprio pensamento; enquanto a verdade do zen se revela na medida em que, quando se chega à origem do pensamento, esta origem mesma do pensamento não existe. A metáfora para se compreender essa ideia é a da fonte de água: ao se descobrir de onde vem a água, a água sempre vem de outro lugar: o ciclo da água permite que falemos de fontes apenas de modo circunstancial e fictício; assim como a água, o pensamento, segundo esse comportamento em relação a ele, também é um fluxo, cuja origem só é origem na medida em que não é. Esse antes do pensamento, o nada, que é o rosto originário do Selbst ou verdade do zen, na medida em que é nada tanto quanto ser, segundo ele, faz com que a verdade do ser não seja nada além de um espelhamento da verdade do zen: mas não nos enganemos, assim como a imagem da lua na água é turva e está em outra dimensão que a lua mesma, também desse modo se comporta esse espelhamento de verdades: a verdade do ser, para Tsujimura, é a sombra do nada absoluto, porque espelha o pensamento antes do pensamento. Dito com outras palavras, o pensamento em sua essência originária é a questão da verdade do ser, e, no entanto, a verdade do ser é sempre a questão da verdade do ser. E na medida em que é a sombra do nada absoluto que a verdade do ser 
é velamento e desvelamento, assim como a abertura originária do nada a partir da totalidade do ente.

Em Identidade e diferença, diz Tsujimura, Heidegger indica essa relação como o pertencer conjunto de ser (a verdade do ser) e pensar (a verdade dos homens) (Tsujimura, 2011, p. 419), e esse pertencer conjunto seria o acontecimento como o instante em que algo é. Tsujimura pensa esse acontecimento tanto como o 'e' do título de Ser e tempo, como também como um turbilhão: mas, para ele, essa noção de acontecimento permanece no exterior desse turbilhão, enquanto o nada absoluto zen é o seu centro estático. Se Heidegger reinterpreta Parmênides contra a sua interpretação tradicional - principalmente contra Hegel (Heidegger, 1975) -, Tsujimura, desse modo, pensa o nada absoluto como o outro início do 'outro início'.

Finalmente, Tsujimura analisa um último aspecto da verdade do ser: ela como alétheia. Esse é, para ele, o aspecto que mais aproxima a verdade do ser da verdade do zen, pois ela é pensada em Heidegger como o não-velamentodo-velado, ou como acontecimento no esquecimento como a privação (Beraubung) (o alfa privativo 'a' de a-létheia) da inverdade (Unwahrheit, létheia). É esse caráter duplamente negativo da verdade concebida por Heidegger que Tsujimura vê como o próprio nada absoluto e aí, ele afirma de modo surpreendente, a verdade do ser e a do zen possuiriam o mesmo lugar, porque compartilhariam o nada absoluto: na verdade do ser há o autossurgimento do nada absoluto. O que não está claro, diz ele, é a relação da questão do ser com o nada absoluto do ponto de vista do nada absoluto surgido; i.e., depois da casa 8 . Ou seja, Tsujimura vê no alfa privativo da verdade como alétheia em Heidegger algo que não é nem o mero nada nem o ser. Em outras palavras, podemos dizer que Heidegger, pelo Logos, por meio de sua interpretação original de Parmênides, teria também chegado ao topo do Everest, ou seja, à casa 8: mas teria ele conseguido voltar para casa? É essa a questão que Tsujimura lega ao seu leitor.

Sem adentrarmos na discussão de se essa interpretação está correta ou não, uma semelhança que encontramos em Ueda e Tsujimura está em ambos verem nos filosófos ocidentais compreensões do nada absoluto até o momento da iluminação e, ao mesmo tempo, não acharem que eles operam a reviravolta afirmativa dessa negação - é verdade que há uma diferença: Tsujimura abstémse de afirmar isso, deixando a tarefa como por se fazer. Ora, essa observação é instigante para pensarmos a própria autodesignação da Escola de Kyoto como escola do nada absoluto (para o Ocidente). De fato, a noção de nada de suas filosofias é bastante desenvolvida, e de fato parece haver diferenças significas e interessantes da sua perspectiva para se pensar uma racionalidade 
não tradicional no Ocidente; mas tanto seria interessante para a própria Escola de Kyoto evitar abusos a respeito da necessidade de o Ocidente aprender com eles essa noção, como é de se pensar de que modo essa mesma perspectiva não aparece como tradicional dentro do âmbito japonês; o tradicionalismo não é obviamente o problema, mas sim o sufocamento de outras perspectivas instigantes e a tendência à postura de aceitação dogmática e inquestionada que este costuma acarretar.

Além disso, ressalta-se, , acima de tudo, a diferença em relação à concepção de nada absoluto de Ueda, quando este o confrontou com a tradição mística alemã de Eckhart e com Nietzsche. Se Heidegger chegou lá pelo Logos, é preciso ressaltar aquilo que não pode ser expressado; se Eckhart e Nietzsche o fizeram pela profunda crítica às ontologias vigentes, então ressalta-se o papel da expressão no conceito de nada absoluto. Qual dos dois autores seguiram de modo mais próprio os passos do inaugurador da Escola de Kyoto? Ou haveria essas potencialidades em seu pensamento? É preciso diferenciar o pensamento autoral de Nishida da filosofia comparativista de seus discípulos; assim como também vale ressaltar que sua filosofia não era necessariamente zen-budista, mas talvez, mais do que tudo, nela estavam presentes diversos elementos da filosofia oriental (Jacinto Zavala, 1994), enquanto seus discípulos já assumem de modo mais desproblematizado o nada do zen-budismo como aquele ao qual se devem comparar os desenvolvimentos da filosofia ocidental. Seria, em contrapartida, esta uma questão com a qual valeira a pena lidarmos? Assumese aqui que esses questionamentos se constituem apenas a preparação para uma real confrontação que visa à possibilidade de um para além da dicotomia Ocidente-Oriente.

Para além disso, percebe-se o eco da grande problemática do desenvolvimento da filosofia no Ocidente no último século segundo uma certa perspectiva, como a de Giannotti (2011): calar-se frente ao que não pode ser dito, ou preencher o abismo entre Logos e além do Logos de possibilidades interpretativas? Poderiam elas ressonar a questão de fundo da filosofia ocidental do século XX, tal como proposto paradigmaticamente por Giannotti, entre Heidegger e Wittgenstein, de se haveria jurisdições de coisas sobre as quais não se deve falar - ou se justamente se deve tentar falá-las a partir de uma ação mais poética e menos científica? Ou seríamos nós, que, ao estudálos, repetimos aqui nossas categorias? 


\section{Referências}

ELBERFELD, R. "Vacuidade e voz media: formas do uso da linguagem em Nishida e Nishitani”. In: Giaccoia Jr., O. e Florentino Neto, A (Org.), 2009, pp. 181-206.

GIACCOIA Jr., O., FLORENTINO NETO, A. (Org.). "Heidegger e o pensamento oriental". Uberlândia: EDUFU, 2012.

. "O Nada absoluto e a superação do niilismo: fundamentos filosóficos da Escola de Kyoto". Campinas: PHI, 2013.

GIANNOTTI, J. A. "Lições de filosofia primeira". São Paulo: Companhia das Letras, 2011.

HEIDEGGER, M.. „Gesamtausgabe”. Frankfurt: Vittorio Klostermann, 1975 et seq. JACINTO ZAVALA, A. "Tres críticas a la Nada absoluta de Nishida Kitarô 19261935: Sôda Kiichirô, Tanabe Hajime y Tosaka Jun”. In: Giaccoia Jr., O., Florentino Neto, A (Org.), 2013, pp. 95-154.

. 'Heidegger na filosofia nishidiana'. In: Florentino Neto (org.) e Giacoia Jr. (org.), 2012, pp.79-108.

. "La filosofía social de Nishida Kitarô 1935-1945". México: El Colegio de Michoacan, 1994.

KÜHNER, R. „Ausführliche Grammatik der griechischen Sprache: Satzlehre”. Hannover: Hahn, 1955.

LEBRUN, G.. "A paciência do conceito: ensaio sobre o discurso hegeliano". São Paulo: Editora UNESP, 2006.

LOPARIC, Z. (org.). "A Escola de Kyoto e o perigo da técnica". São Paulo: Dww, 2009.

MÜLLER, M. L. "A Experiência religiosa e a lógica tópica da autodeterminação do presente absoluto (Kitaro Nishida)”. In: Giaccoia Jr., O. e Florentino Neto, A. 2009, pp. 149-180.

NISHIDA, K. „Über das Gute: eine Philosophie der reinen Erfahrung”. Tradução de Peter Pörtner. Frankfurt a.M.: Insel Verlag, 2001.

. "Last Writings: nothingness and the religious worldview". Honolulu: Univ. of Hawaii Pr., 1987.

. "Kitarô Nishida: Selbstidentität und Kontinuität der Welt". In: Ohashi (org.), 2011, pp. 56-114.

NISHITANI. "The self-overcoming of nihilism”. Nova Iorque: State University Press, 1990.

OHASHI, R. (org.). „Die Philosophie der Kyôto-Schule”. Freiburg i.. Breisgau: Karl Alber Freiburg Verlag, 2011.

SMYTH, H. W. "Greek grammar”. Oxford: Benediction Classics, 2010.

TSUJIMURA, K. „Kôichi Tsujimura: Die Wahrheit des Seins und das absolute Nichts". In: Ohashi (org.), 2011, pp. 413-425.

UEDA, S. „Wer und was bin ich? - zur Phänomenologie des Selbst im ZenBuddhismus". Freiburg i. Breisgau: Verlag Karl Alber, 2011a. 
. „Shizuteru Ueda: Das absolute Nichts im Zen, bei Eckhart und bei Nietzsche”. In: Ohashi (org.), 2011b, pp. 440-468. / Trad.: "O nada absoluto no Zen em Eckhart e em Nietzsche". Natureza Humana, São Paulo, Vol. 10, Nr. 1, pp. 163-202, junho de 2008 [Online] Disponível em: <http://pepsic.bvsalud.org/scielo.php?script=sci arttext\&pid=S1517-24302008000100008\&lng=pt\&nrm=iso $>$. (Acessado em: 28 de maio de 2015). 